\title{
Vitamin D and Obesity in Adult Populations in Egypt: The Vitamin Inadequacy in Association with Visceral Fat Distribution
}

\author{
Raouf M Afifi'1,2, Mostafa M Sadek ${ }^{3,4}$, Ashraf E Saad ${ }^{5,6}$ and Sameh S Zaytoun ${ }^{7}$ \\ ${ }^{1}$ Community Health Research Institute, International Management-Health Services, USA \\ ${ }^{2}$ Health Research Institute, SA Consultancy \& Training, Egypt \\ ${ }^{3}$ Sadeklab Laboratories, Egypt \\ ${ }^{4}$ Microbiology and Public Health Department, Military Medical Academy, Egypt \\ ${ }^{5}$ Department of Preventive Medicine, Armed Forces Hospital at Wadi Al-Dawasir, KSA \\ ${ }^{6}$ Department of Statistics and Information, Ministry of Health, Sudan \\ ${ }^{7}$ Community Medicine \& Public Health Department, South Valley University, Egypt
}

Submission: December 13, 2018; Published: February 22, 2019

*Corresponding author: Raouf Afifi, Community Health Research Institute, International Management-Health Services, 13835 Azalea Circle, Tampa, FL, USA

\begin{abstract}
Background: Both obesity and vitamin D inadequacy are closely related; yet the relationship between body fat (BF) distribution pattern and vitamin D concentration needs further scrutiny.
\end{abstract}

Study Aim: Analyze the relationship between visceral fat area (VFA) and impaired vitamin D levels among Qena populations, Upper Egypt.

Methods: Adults aging 20 and above seeking care at the outpatient department (OPD) of Qena University Hospital (QUH) have been examined, fatness indices including body mass index (BMI) and waist circumference (WC) measured, and VFA assayed using bioelectrical impedance analysis (BIA). Visceral fat obesity (VFO) was specifically measured in association with serum vitamin D3 [25(OH) D3)] level.

Results: The study comprised 420 subjects, 246 men, 174 women (125 pre-menopausal, 49 post-menopausal). Subjects' VFO (46.2\%) was higher than overall obesity (21.2\%); men had higher VFO indices [median (IQR)] vs. women: BMI=28.8(13) vs. 25.4(4), WC=95.2(5) vs. 82.8(8), VFA $=117.3(27)$ vs. 85.5(26), respectively. Men had a lower 25(OH) D3 [31.1(14.3)] level than women [36.2(19)]. The prevalence of vitamin D deficiency (VDD) accounted 35.5\% in men and 23.7\% in all women ( $\mathrm{p}=0.009)$. Subjects' 25(OH) D3 levels [median (IQR)] and VFA quartiles (Qs) were inversely related both in men [38.8(18), 31.4(15), 28.8(16), 23.2(14), $p=0.005]$ and pre-menopausal women [42.7 (26), 41.2 (25), 36.8 (21), $\mathrm{p}=0.03]$. Only men suffer increasing vitamin $D$ insufficiency across VFA quartiles ( $Q 1=10.1 \%, Q 2=13.3, Q 3=37.7, Q 4=39.8, p=0.002)$; while both men and pre-menopausal women sustain escalating VDD pattern under VFA quartiles (Q1 20.1\%, Q2 39.6, Q3 45.2, Q4 55.3, p<0.0001), (Q1 18.7\%, Q2 20.3, Q3 23.6, Q4 37.1, p =0.00032), respectively. Men and pre-menopausal groups with the highest VFA were prone to 25(OH) D3 insufficiency/deficiency, compared with the lowest VFA groups [OR men 5.7 (95\% CI $3.1-9.2$; p=0.02), OR women 95\% CI 2.2 - 4.5, p=0.009].

Conclusion: Higher VFA may be risk for vitamin D inadequacy in men and pre-menopausal women. That VFA assessment using BIA provides a sex-specific adiposity measurement in identifying vitamin D inadequacy; VFA can be used as a simple and cost-effective instrument in population-based screening to prevent VDD, especially among high risk groups.

Keywords: Obesity; Visceral fat obesity; Visceral fat area; Vitamin D3; Inadequacy

Abbrevations: WHO: World Health Organization; BMI: Body Mass Index; CHD: Coronary Heart Disease; AT: Adipose Tissues; WHR: Waist-ToHip Ratio; DEXA: Dual Energy X-Ray Absorptiometry; VFO: Visceral Fat Obesity; BMC: Bone Mineral Composition; CT: Computed Tomography; MRI: Magnetic Resonance Imaging; VAT: Visceral Adipose Tissue; BIA: Bioelectrical Impedance Analysis; VDR: Vitamin D Receptors; IGT: Impaired Glucose Tolerance; VFA: Visceral Fat Area; ALP: Alkaline Phosphatase; iPTH: Intact Parathyroid Hormone; FFAs: Free Fatty Acids; RANKL: Receptor Activator of Nuclear Factor -кB Ligand; OPD: Outpatient Department; DEFF: Design Effect; HPLC: High-Performance Liquid Chromatography; IRS: Interval Ratio Scale; SD: Standard Deviation; IQR: Interquartile Range; PMTs: Parametric Techniques; OR: Odds Ratio; CI: Confidence Interval; HOMA-IR: Homeostasis Model Assessment of Insulin Resistance 


\section{Introduction}

Obesity is a significant health problem worldwide of some variability in its prevalence and burden, being worse in developing countries [1]. Despite the relentless international and national works to control the obesity problem, the prevalence of obesity with its associated risks and health derangements is on the rise. According to the World Health Organization (WHO), obesity has more than doubled since 1980, [2] and as of 2003, a number of 1.7 billion overweight/obesity persons was estimated [3]. By 2014, more than 1.9 billion adults 18 and older were overweight, including 600 million who were obese [2]. These figures represent $39 \%$ and $13 \%$ of adult population, respectively.

Using the WHO classic definitions [body mass index (BMI) 25 $\mathrm{kg} / \mathrm{m} 2$ = overweight, BMI $30 \mathrm{~kg} / \mathrm{m} 2$ = obese] and factoring the estimated overweight and obesity rates globally, governments are often condemned of being insufficiently capable and oriented of the most major risks to health affecting the world's population [4]. The excess weight of the enlarged adipose tissue mass together with the metabolic changes of obesity can induce serious health problems, increasing the risk for many chronic ailments. For instance, obese persons have more than double risk to have hypercholesterolemia than others. Diabetes is also known with its strong positive relationship with obesity, and peculiarly potentiating the state of insulin resistance [5]. These conditions, as well as other sequelae, such as nutritional deficiencies, coronary heart disease (CHD), HTN, and stroke can be prevented or reduced by weight loss, even by modest weight loss [6].

\section{Mechanisms and precipitating factors of obesity}

Several factors have been incriminated in the development of obesity, including:

a) Genetic factors, e.g. variants of leptin gene that causes a deficiency of the leptin hormone responsible for modulation of eating behavior and regulation of adipose proliferation [7],

b) Energy imbalance where caloric consumption exceeds the need,

c) Fat cell theory, such that an increased proliferation of fat cells and adipose tissues (AT) during childhood predisposes to adulthood obesity [8],

d) Behavioral factors, including irresistance to eating when food is available and eating when depressed, and

e) The central regulation theory that incorporates the affection of hypothalamus upon the development of improper appetite control [9]. The low-socioeconomicstatus and minority groups of all ages were more affected by increased BMI than those who were otherwise [10].

\section{Obesity identification and assessment}

Commonly used anthropometric weight and body mass (BM) techniques include BMI, WC and waist-to- hip ratio (WHR) [11]. While BMI stands as a practical estimate of adiposity in adults, results may often need to be interpreted with caution. Now that most common methods for diagnosing overweight and obesity are based on BMI and that BMI is suboptimal marker for total $\mathrm{BF}$ percentage or assessing $\mathrm{BF}$ distribution [11], total BF content could be assessed through body composition measurement techniques, such as "dual energy x-ray absorptiometry" (DEXA) [12]. In people with a $\mathrm{BMI}<35, \mathrm{WC}$ may be used in addition to BMI.

On the other hand, WHR is a useful measure of obesity and simple yet efficient anthropometric index for predicting a wide range of risk factors and related health conditions. Central obesity and visceral fat obesity (VFO), approximated by $\mathrm{WC}$ is known to generate diabetogenic substances and may often be perceived as being more informative [8,13]. From the statistical perspective, BMI and WC are generally unlikely to yield different answers $[11,13]$. In a retrospective study on the use of WC to predict insulin resistance on a sample of 2746 healthy volunteers, a $\mathrm{WC}<100 \mathrm{~cm}$ excluded individuals of both sexes from being at risk of being insulin resistant [13]. However, there is no consensus about the best cut-off points to be used for identifying individuals at risk. Some suggested using two cut-off points for each gender based on established cut-off points for BMI: WC $>94 \mathrm{~cm}$ (overweight) and WC $>102 \mathrm{~cm}$ (obese) in men and for women $\mathrm{WC}>80$ and $\mathrm{WC}>88 \mathrm{~cm}$, respectively [13]. Others proposed $\mathrm{WC}>100 \mathrm{~cm}$ for adults $\leq 40$ years and $\mathrm{WC}>90 \mathrm{~cm}$ for adults $>40$ years, for both men and women.

\section{Body composition and BF assessment}

Evaluation of the body composition is used to describe the percentages of fat, bone, water and muscle in human bodies. Several methods are known to evaluate and measure body components proportions, with variable degree of sophistication and acceptance. Especially FM proportion has been focus for a range of chronic disease risks and obesity research [14]. Although $\mathrm{BF}$ percentage has been strongly associated with the risk of several chronic diseases, its accurate measurement is difficult. Mathematically, rather accurate estimate of body composition, including BF, is derived from "body density" (= mass/volume), by means of the equation of "fractional densities" (densitometry calculation) [15]. More recently, body composition started to be measured with radiographic scans, e.g., DEXA [16]. The latter gives accurate measurements of body composition, including bone mineral composition (BMC) and BM density, lean tissue mass, FM, and fractional contribution of fat, thereby considered as the gold standard in body composition testing above underwater weighing techniques, and the likes [17]. Other methods to measure body constituents include computed tomography (CT) and magnetic resonance imaging (MRI) 


\section{Current Research in Diabetes \& Obesity Journal}

scans, sulfur hexafluoride dilution method, air displacement plethysmography [18], however they are expensive and/or bound to radiation exposure hazard.

\section{Measuring VFO}

Numerous techniques have been developed to assess visceral adipose tissue (VAT). Clinically expedient, yet they still are indirect, techniques to measure visceral adiposity provide instant results since they are performed by the bedside. Examples are BMI, WC and WHR measures, as well as "bioelectrical impedance analysis" (BIA) [12]. On the other hand, CT and MRI provide direct measures of cross-sectional areas or volumetric measures of VAT. Especially BIA has been found to predict DXEA-derived percentage BF with a higher correlation with that acquired by DEXA, CT and MRI $[17,18]$. Using BIA is primarily based on electric resistance difference between fat and other organ components and that BF impedes electric current more than body protein. (Impedance encompasses a drop-in voltage when a small current with fixed frequency passes between electrodes spanning the body). Lean tissue (rich in water and electrolytes) though has minimal impedance and increases to a maximum when all lean tissue is replaced by fat/adipose tissue. Hence, lean BM and FM can be calculated from the difference in conductivity [12].

\section{Vitamin D and obesity}

Recently, overweight and obesity have been shown to be related to low vitamin D status [12]. Around one billion people worldwide suffer from VDD [19-21] which may result from limited exposure to sunlight, long-term wearing of covering clothes, use of sunscreen, age as well as low consumption of food containing ergocalciferol (vitamin D2), and malabsorption syndrome [22,23]. Vitamin D receptors (VDR) and the $1 \alpha$-hydroxylase enzyme, which catalyzes the conversion of calcidiol [25-hydroxyvitamin D, or 25(OH) D] to calcitriol [1,25-dihydroxyvitamin D, or activated vitamin D 1,25(OH)2 D], were found in more than 40 human cell types $[19,23,24]$ indicating its potential role in the regulation of numerous metabolic processes.

Further, there may be a connection between vitamin D levels and cardiometabolic diseases collated in the "metabolic syndrome [25]." The latter involves a combination of obesity, impaired glucose tolerance (IGT) and type 2 DM; HTN, and atherogenic dyslipidemia [26]. Although the mechanisms are still unclear, VDD is associated with a greater risk of such pathological conditions [21,23,27-29] On the other hand, an increased BF and obesity may well be associated with low circulating $25(\mathrm{OH}) \mathrm{D}$ level $[14,5,30]$. As before $[11,13], \mathrm{WC}$ is recognized as a risk for VDD, there might be substantial variations in the visceral fat area (VFA) amount in persons with a similar WC because WC itself performs poorly in discriminating between visceral and subcutaneous fat [12]. Therefore, it is possible that subjects with a normal WC may be more prone to VDD if they have centrally located BF.

\section{Obesity-vitamin-D relationship directionality}

Research shows an extraordinarily high prevalence of VDD afflicting a high proportion of both elderly and younger populations [31,32]. In the study of predominantly medical inpatients in Boston [32], 57\% of young adults were vitamin D deficient $[25(\mathrm{OH}) \mathrm{D} \leq 15 \mathrm{ng} / \mathrm{ml}], 22 \%$ of whom had a severe deficiency $[25(\mathrm{OH}) \mathrm{D} \leq 8 \mathrm{ng} / \mathrm{ml}$. Lower vitamin D intake, less exposure to ultraviolet light (UVL), anticonvulsants, dialysis, nephrotic syndrome (NS), HTN, DM, higher intact parathyroid hormone (iPTH) and alkaline phosphatase (ALP), and lower serum concentrations of $\mathrm{Ca}+2$ and albumin were predictors of hypovitaminosis $\mathrm{D}$.

Unexpectedly, $43 \%$ of those with vitamin D intakes at or above the recommended daily allowance were also vitamin D-deficient [32]. In another Boston study of predominantly medical workers, $30 \%$ of young adults were found to be deficient $[25(\mathrm{OH}) \mathrm{D}<20$ ng $>2$ ] at the end of winter, while $11 \%$ were deficient at the end of summer [33]. In their pursuit of exploring the strength and directionality of the relationship between obesity and vitamin $D$, researchers may have been influenced by the hypothesis that obesity can be risk factor for decreased vitamin D levels [25,34]. In practice, it has been consistently observed that increased FM and obesity both predispose to lowered circulating 25(OH) D levels $[12,14,35,36]$, in a straightforward assumption about the temporal relationship between high BMIs and decreased vitamin D level and its impaired metabolic pathways [37].

As such, it has been postulated that a maintained vitamin D level could be among the protective factors against obesity and increased FM in risky people $[14,29,38,39]$. This could also have a role in the development of the metabolic syndrome, or any of its individual aggregates $[21,23,25,27,38]$. Despite a consistent link between vitamin D and obesity, the exact explanations of causality are still unclear. Providing compelling evidence to the inquiry "is obesity an independent factor for VDD or is it VDD that independently predisposes to exaggerated FM and obesity; or is it a little of both" yet is still awaited [36]. In the presence of the epidemic prevalence of obesity $[2,3]$ and the prevalence of impaired vitamin D levels among today's populations [19-21], conducting large-scale experiments recruiting a large size of controls to track the variability in vitamin D levels against body weight and record accurate diet history over years of study is warranted yet rather difficult.

However, in the study by Leblanc et al. [39] on 9704 US cohort of women aged $\geq 65$, higher vitamin levels were consistently associated with lower weight gains, suggesting hypovitaminosis D may predispose to fat accumulation. In the laboratory, $1,25(\mathrm{OH}) 2 \mathrm{D}$ may influence the mobilization of free fatty acids (FFAs) from the adipose tissue as well as metabolism of fat cells, whereas randomized controlled trials in human showed a similar, but a modest weight reduction with vitamin D supplementation [36]. Baseline 25D concentrations were examined in relation to prevalent and cumulative incident obesity in a study of 2460 


\section{Current Research in Diabetes \& Obesity Journal}

adults; whereas in addition to prevalent obesity, serum 25D concentrations $<50 \mathrm{nmol} / \mathrm{L}$ were significantly associated with new-onset obesity [40]. Although this does not prove a causative effect, it is highly suggestive and warrants further research.

Vitamin D biophysiology: Vitamin D3 (cholecalcifereol) is synthesized in the skin [after UVL exposure] or consumed, and then is stored until needed. When the serum concentration of vitamin D is below normal, both intestinal calcium and phosphorus absorption decrease. Calcitriol stimulates intestinal calcium absorption by interacting with vitamin $\mathrm{D}$ receptors in the small intestine. The net effect is an enhancement of calcium entry through an epithelial calcium channel [31]. Therefore, calcitriol's major biologic activity on bone is indirect: to promote passive mineralization of collagen matrix (osteoid) by maintaining extracellular calcium and phosphorus in a supersaturated state.

Vitamin D is 25-hydroxylated in the liver in a largely unregulated step and activated to calcitriol by $25(\mathrm{OH}) \mathrm{D}-1-\alpha$ hydroxylase in the kidney [41]. In the physiological state of calcium deficiency, iPTH levels rise resulting in renal 1-hydroxylation of $25(\mathrm{OH}) \mathrm{D}$ and increased production of $1,25(\mathrm{OH}) 2$ D. Calcitriol interacts with the vitamin D receptors on osteoblasts to generate "receptor activator of nuclear factor $-\kappa B$ ligand" (RANKL) on their surface membrane. Interaction with the RANK receptors on pre-osteoclasts induces maturation to fully mature osteoclasts that are essential for osteoclastic bone resorption with subsequent release of calcium into the extracellular space $[41,42]$.

The main dietary sources of vitamin D are vitamin D fortified milk, margarine and cereal, although fish, liver and egg yolks are good but lesser sources. Sun exposure (UV-B light) is the predominant source of vitamin $\mathrm{D}$ via photo-conversion of vitamin D precursors to pre-vitamin D3 in skin. Depending on the latitude, 15-30 minutes of direct daily spring/ summer/ fall midday sun exposure is sufficient to provide all vitamin $D$ requirements [31]. An elderly person over the age of 70 produce $<30 \%$ of the vitamin D of a young person with the same sun exposure [42]. This, combined with less efficient vitamin D intestinal absorption, makes the elderly shut-in patient particularly susceptible to VDD. Significant amounts of vitamin D supplements must be supplied to overcome these effects.

\section{Definition, prevalence and burden of VDD}

Assessment of vitamin $\mathrm{D}$ depot is best done by measurement of $25(\mathrm{OH})$ D. The definition of normal levels of $25(\mathrm{OH}) \mathrm{D}$ has changed in recent years as the effects of mild VDD have become known. Most commercial laboratories still use $9-15 \mathrm{ng} / \mathrm{ml}$ as the lower limit of normal for vitamin D. Despite the controversy, optimal serum levels to avoid increases in iPTH are at least 20 $\mathrm{ng} / \mathrm{ml}$; meanwhile investigators have suggested the appropriate serum level is $32 \mathrm{ng} / \mathrm{ml}$ [43]. Several reviews have found high prevalence of VDD worldwide [44,45], even in countries with low latitude, where it was generally assumed that UVB radiation was adequate enough to prevent VDD, and in industrialized countries, where vitamin D fortification has been implemented now for years. The one-billion-figure hypovitaminosis D subjects, worldwide [19-21] supposedly involves all ethnicities and ages. Strikingly, almost one-third of the developed populations may be suffering hypovitaminosis D [24]. The situation in the Middle East and the North African region is worse, and it is more prominent in women of varying ages [46].

Obesity, and a higher muscle mass play a principal role in the majority of vitamin D biophysiological derangements [19,23,24], given the vitamin's fat-soluble nature which implies BF may act as a "sink" by collecting the vitamin [31]. The clinical consequences of VDD include osteomalacia, increased susceptibility to fragility fractures, bone pain, and muscle weakness. Vitamin D deficiency should be suspected in patients who have fat malabsorption syndromes (e.g., Crohn's Disease, intestinal bypass surgery) $[22,23]$. It has been also found that elderly patients with the low vitamin D level were 11-folds prone to be depressed than those who received healthy doses [47]. Change in serotonin level; (rises with exposure to bright light and diminishes with darkness) could be behind this association. Vitamin-D deficiency has also been incriminated in bone aches, especially in combination with fatigue conditions [48]. Drug, such as phenytoin, phenobarbital, cadmium, rifampin and cholestyramines are known to interfere with vitamin D metabolism and absorption [49]. Less commonly, there are several known inherited disorders of metabolism of $25(\mathrm{OH}) \mathrm{D}$ to $1,25(\mathrm{OH}) 2 \mathrm{D}$ [50], most of which result in a secondary hyperparathyroidism (with subsequent osteoclastic activity and proneness to fragility fracture).

Treatment and prevention of VDD: A commonly used strategy to treat VDD is to start two initial episodes of vitamin D 280,000 IU each as 40,000 IU weekly for 7 weeks then $4,000 \mathrm{IU} / \mathrm{d}$ for 10 weeks, followed by a daily maintenance dose of 800-2000 IU [51]. One caveat is the considerable variability in serum vitamin D levels between laboratories [52]. Clearly, standardization of $25(\mathrm{OH}) \mathrm{D}$ measurements is essential. However, a target point recommended for VDD generally is $>30 \mathrm{ng} / \mathrm{ml}$. The combination of vitamin $\mathrm{D}$ and calcium supplementation has been shown to reduce the incidence of non-vertebral and hip fractures in large controlled experiments of elderly men and women [53].

Factoring the peculiar relationship between $25(\mathrm{OH}) \mathrm{D}$ on the one hand and BMI and FM setup, stabilization of either component entails stabilization of the other. Obesity, in turn is one of the most difficult and discouraging problems to treat. Several therapeutic approaches to reduce weight are still feasible, including specialized nutritional and exercise programs, which constitute the main measures for weight reduction. Jeffery and French reported that as a modest weight loss as $10 \%$ or perhaps even $5 \%$ of body weight is sufficient to control most complications of obesity. Therefore, there is no reason to pursue 


\section{Current Research in Diabetes \& Obesity Journal}

the traditional goal of attaining an ideal body weight, which is so seldom attained, and if attained, is so rarely maintained [54].

That VDRs have been demonstrated in adipocytes, adipose tissue is responsive to vitamin D [55-57], and that obesity and vitamin D are such correlated [12,34,39], through mechanisms involving adipose tissue distribution, a sustained prevention and control of either entity supports adequacy of the other. When indicated, surgical intervention for weight loss and can result in resolution of morbid obesity and related comorbidities $[19,58,59]$. Complications past-surgery vary based on the procedure performed and can be as high as $40 \%$ [60]. Particularly, nutritional deficiencies can develop. Common deficiencies include vitamin B12, folate, zinc, iron, copper, vitamin D and calcium $[45,52,61]$, thereby maintained dietary replacement of these substances should begin shortly after surgery.

The high prevalence of obesity constitutes a heavy burden upon the public health system and national economy. In turn, VDD may be another health problem overwhelming the Egyptian population's health with little signs to wane off in the foreseen future; both conditions have consistently been occurring in parallel, whether in the same individual or the same population. Given the scarcity of knowledge, if any, about the prevalence of VDD states among adult obese individuals in Upper Egypt, this study was performed to explore the presence and size of this relationship among a sample of obese Qena residents with or without comorbid chronic diseases and correlates. The distinctive difference in fat distribution pattern between men and women, as well as between pre-menopausal and postmenopausal women and its effect on serum 25(OH) D3 levels supports selecting VFO assessment via BIA to achieve study goal. Findings from this work can be of help in planning for a remedial strategy to control and prevent the escalating obesity- vitamin D health problem which has been encountering the national health system since decades and throughout the foreseen future.

\section{Methods}

The study was conducted at the outpatient department (OPD) setting of QUH. A cross-sectional design was selected to achieve study aim. Adult care seekers currently registered in QUH medical information system either Qena residents or those referred from affiliated institutions in surrounding governorates were targeted. The study cohort constituted subjects aged 19 and above from both sees coming to OPD either upon appointment, walking in or referrals during mid-October-to- November 2016. Selected OPD clinics included internal medicine, family medicine, medical subspecialties, nutrition, ophthalmology, and ENT. No subject was enrolled if any of the conditions affecting vitamin D metabolism was found, including osteoporosis, being on hormone replacement therapy, liver disease, kidney disease, being on diuretics, hyperparathyroidism, hyperthyroidism, infectious diseases, psychiatric disease, presence of tumor and lymphomas $[41,62]$. Having malabsorption as in celiac disease and Crohn's disease [24], syndromal obesity, severe disability, occurrence of bone fracture within the past six months and having stents or history of CVD were exclusion causes. Pregnant women were also not enrolled. Importantly, all subjects should not have had previous history of weight loss- bariatric surgery.

\section{Sampling}

Epi InfoTM software (version 7.2) (http://www.openepi. com/SampleSize/SSPropor.htm) for sample size -population fraction calculation was used, with the following assumptions: a) population size " $N$ " $=1000,000$, b) hypothesized $\%$ frequency of VDD in the population (P): $35 \% \pm 5$, c) confidence limits as $\%$ of 100 (absolute $\pm \%$ ) (d)=5\%, and d) design effect (DEFF): 1. A sample size " $n "=349$ was obtained. In order to make up for incomplete data, invalid responses, and withdrawals, an estimated $20 \%$ increase in calculated "n" would be added, so 420 subjects $(\approx 349 * 1.2$ ) would be recruited.

The study sample frame consisted of people from the general population seeking care with QUH which can include subjects of weight and BF ranging from underweight - up to obesity with or without comorbidity, as well as subjects with different vitamin-D levels. The OPD clinics would be attended daily as 10 days a week (Sunday-Thursday) during working hours, patient flow rate identified, and both new and follow-up visits randomly selected until all required sample size has been accomplished, depending on the daily rate of patient visit, following a systematic sampling approach (essentially every third adult visitor). That said, we were able to recruit 10 subjects per day on average until all 420 subjects were recruited in the study's $2 \frac{1}{2}$ month duration [10 patients/d $* 5$ days/week $\approx 50$ patients/week; $420 / 50 \approx 81 / 2$ weeks $\approx 21 / 2$ months].

\section{Data collection tools}

A validated version of the "Behavioral Risk Factor Survey" questionnaire in Arabic was used [63]. It consists of 44 "items" (questions) in 5 scales, important of which are: a) demographic criteria, b) risk factors (e.g., smoking and drinking behaviors); c) lifestyle (e.g., eating habits, diet indicators, exposure to sun, daily time spent outdoors, sunscreen use, PA, and vitamin D supplement), and d) health and disease status (e.g., HTN, DM, CVD, dyslipidemias, and menopausal status). A woman was considered post-menopausal if she reported menses had ceased for 1 year or more, and age at menopause was self-reported as previously reported. The questionnaire takes 20-25 minutes to complete. Participants were first informed of the study aim, and it was made clear that participation was voluntary. They were also reassured of the confidentiality of the provided information. A verbal consent from participants was considered a personal permission to take part in the study. Only returned questionnaires with valid answers on $\geq 80 \%$ of the items were included in the analysis.

A proforma including reviewed medical data with BMI, WC, BP, measurements, comorbid conditions, provisional diagnoses, laboratory results, and management plans, was designed. 
Cases then submitted to clinical examination to identify their obesity, and also confirm and complete all required clinical data, including measurements, comorbidities, cardiometabolic disorders such as T2DM, HTN, sleep apnea or other respiratory disorders, lipid abnormalities, gastrointestinal disorders and CVD. Blood pressure (mmHg) was measured at the right arm in sitting position, using mercurial sphygmomanometer and stethoscope after 10 a minute rest in the supine position then record systolic and diastolic BP. A cuff of a size appropriate to the arm circumference was used. Hypertension would be defined as a SBP of $140 \mathrm{mmHg}$ or higher (or a diastolic BP of $90 \mathrm{mmHg}$ or higher) [64].

\section{Anthropometric measurements}

Weight was measured to the nearest of $0.1 \mathrm{~kg}$ on physician balance beam scales wearing light clothes and with no shoes. All scales were identical and calibrated with a standard Inter ASIA protocol [63]. Height was measured without shoes to the nearest of $0.1 \mathrm{~cm}$ using a stadiometer. Subsequently, BMI was calculated [BMI = weight $(\mathrm{kg}) /$ height $(\mathrm{m} 2)]$. Results of BMI were compared to the following standard: $<18.5 \mathrm{~kg} / \mathrm{m} 2=$ underweight, $18.6-24.9 \mathrm{~kg} / \mathrm{m} 2=$ normal weight, $25-29.9 \mathrm{~kg} / \mathrm{m} 2=$ overweight, $>30 \mathrm{~kg} / \mathrm{m} 2=$ obese [12]. Waist circumference was measured mid-way between the lateral lower ribs and the iliac crest, as per standardized WHO STEPS protocol [65], using tape measure, with cut-off points for men: WC $>94 \mathrm{~cm}$ [consistent with BMI $25-<30$ (overweight)] and $\mathrm{WC}>102 \mathrm{~cm}$ [consistent with $\mathrm{BMI} \geq 30$ (obese)]; and cutoff points for women as WC>80 (consistent with overweight and $\mathrm{WC}>88 \mathrm{~cm}$ (consistent with obesity) [13]. Waist circumference could be used to reflect our individuals' VFO condition. In which case, VFO is considered with WC $\geq 102$ $\mathrm{cm}$ for men and $\mathrm{WC} \geq 88 \mathrm{~cm}$ for women [66].

\section{Abdominal VFA estimation by BIA}

Novel VFA as a sex-specific index for VFO [67] was used to analyze the association of 25(OH)D3 level and VFO in our study population [68]. Abdominal VFA was estimated using "multifrequency BIA machine" (Inbody720(R); Inbody Co.) for the subjects in a fasting state on the same day as their blood test. Subjects were requested to refrain from smoking and strenuous exercise for $48 \mathrm{~h}$ prior to measurement. After the subjects had been guided to stand on the platform of the device, age and gender information were entered into the machine. After confirming that the subject was standing correctly with both arms $45^{\circ}$ apart from the body and both feet correctly placed on platform, a supervisor pushed the start button to perform assessment. In the study, VFO is defined as a VFA exceeding 130 $\mathrm{cm} 2$ in men and $100 \mathrm{~cm} 2$ in women [69]. This VFO definition well coincided with $W C \geq 102 \mathrm{~cm}$ for men or $\geq 88 \mathrm{~cm}$ for women [66].

\section{Biochemical analyses}

Tests of our focus included: serum vitamin D level [25(OH) D], fasting plasma glucose (FPG) level, lipid profile, and serum
25(OH) D3 level. Diabetes was diagnosed as per the WHO standard as "FPG $\geq 126 \mathrm{mg} / \mathrm{dl}$ [70]." High total cholesterol was defined according to the Adult Treatment Panel III (ATP III) guidelines as $\mathrm{TC} \geq 240 \mathrm{mg} / \mathrm{dl}$ [71]. Total serum 25(OH) D3 level was assayed by the high-performance liquid chromatography (HPLC) method [12]. A serum level of $25(\mathrm{OH}) \mathrm{D} 3<20 \mathrm{ng} / \mathrm{ml}$ was considered VDD, whereas $20-<30 \mathrm{ng} / \mathrm{ml}$ insufficient; and to maximize vitamin D effect for health, 25(OH) D3 should be $\geq 30$ $\mathrm{ng} / \mathrm{ml}(\geq 75 \mathrm{nmol} / \mathrm{L})[20]$.

\section{Statistical analysis}

Most of the entered variables involved anthropometric and biochemical data e.g., age, BMI, WC, VFA, FPG, TC, were interval ratio scale (IRS). These were principle covariates the effect of which on 25(OH) D3 level, as the dependent variable (IRS) of interest would be assessed. Collected data were entered to MS program with adequate back up; open-ended questions coded, and observations made ready for statistical analysis. First, descriptive statistics, including frequency data, would be displayed. Quantitative data will be summarized as mean \pm standard deviation (SD), range, quartiles (Q1, Q2, Q3, Q4), or median and interquartile range (IQR), where appropriate. Quantitative data were summarized as count (\%).

Analytical statistics includes parametric techniques (PMTs), e.g., student t-test comparing the mean difference between two independent groups. [Normality would be first assessed us using one sample Kolmogorov-Smirnov (K-S) test; otherwise, non-PMT alternatives such as Mann-Whitney-U test, would be calculated]. Testing the difference between more than two groups in their observed levels of the continuous outcome variable that is skewed, Kruskal Wallis test would be calculated. Either a Pearson's correlation or a Spearman's correlation, depending on normality distribution to compare the strength of correlation between selected continuous variables could be attempted.

Non-PMT techniques, e.g., chi-square test (or Fisher's exact, where appropriate) would be used for the relationship between categorical variables. In which case, the odds ratio (OR) with the 95\% confidence interval (CI) could be used. The SPSS (Chicago, IL) software- version-20 was used for statistical analyses. All tests were done at level of significance $a=0.05$; results with p-values $<0.05$ considered "statistically significant." A pilot administration was first performed, and an acceptable - strong reliability for the questionnaire's items and scales was found (rho $=0.7$ or above).

\section{Ethical approval}

The study was conducted in accordance with the Declaration of Helsinki; required permissions, including arrangement with QUH management and OPD officials were obtained. Further, approval of QUH research ethics committee to perform the study and access QUH under guidance for the study purpose was granted. 


\section{Current Research in Diabetes \& Obesity Journal}

Results

Table 1: Distribution of the study group by anthropometric biochemical criteria

\begin{tabular}{|c|c|c|c|c|c|}
\hline \multirow[t]{2}{*}{ Characteristics } & \multicolumn{2}{|c|}{ Observation Value } & \multirow[t]{2}{*}{ Test Statistic } & \multirow[t]{2}{*}{ p-Value } & \multirow[t]{2}{*}{ Total } \\
\hline & Male & Female & & & \\
\hline Age (y) (IQR) & $44.2(13)$ & $39.1(11)$ & $\mathrm{U}=19228.0$ & 0.076 & $42.3(13)$ \\
\hline BMI (kg/m²) (IQR) & $28.8(5)$ & $25.4(4)$ & $\mathrm{U}=15634.0$ & 0.001 & $26.6(5)$ \\
\hline WC (cm) (IQR) & $95.2(10)$ & $82.8(8)$ & $\mathrm{U}=17945.0$ & $<0.0001$ & $89.8(8)$ \\
\hline VFA $\left(\mathrm{cm}^{2}\right)(\mathrm{IQR})$ & $117.3(27)$ & $85.5(26)$ & $\mathrm{U}=13416.0$ & 0.003 & $92.4(30)$ \\
\hline SBP (mmHg) (IQR) & $123.7(16)$ & $109.3(12)$ & $\mathrm{U}=14762.0$ & $<0.001$ & $110.6(13)$ \\
\hline $\begin{array}{l}\text { Total cholesterol (TC) } \\
\quad(\mathrm{mmol} / \mathrm{L})(\mathrm{IQR})\end{array}$ & $5.9(1.1)$ & $5.0(0.9)$ & $\mathrm{U}=12430.0$ & 0.12 & $5.3(1.0)$ \\
\hline $\mathrm{FPG}(\mathrm{mmol} / \mathrm{L})$ & $6.1(1.0)$ & 5.4 (IQR 0.9) & $\mathrm{U}=14041.0$ & 0.012 & $5.7(1.2)$ \\
\hline 25(OH)D3 ( $\mu \mathrm{g} / \mathrm{L})(\mathrm{IQR})$ & $31.1(14.3)$ & $\begin{array}{l}36.2 \text { (IQR } \\
\text { 19) }\end{array}$ & $\mathrm{U}=12743.5$ & 0.004 & $35.1(20.4)$ \\
\hline Obesity (\%) & $\begin{array}{c}17.5 \\
(43 / 246)\end{array}$ & $\begin{array}{c}26.4 \\
(46 / 174)\end{array}$ & $X^{2}(\mathrm{df} 1)=4.9$ & 0.029 & $21.2(89 / 420)$ \\
\hline \multicolumn{6}{|l|}{ VFO (\%) } \\
\hline $\begin{array}{c}\text { WC: } \operatorname{men} \geq 102 ; \text { women } \geq 88 \\
(\mathrm{~cm})\end{array}$ & $\begin{array}{c}50.2 \\
(=123 / 245)\end{array}$ & $\begin{array}{c}40.4 \\
(=70 / 173)\end{array}$ & $X^{2}(\mathrm{df})=3.9$ & 0.047 & $46.2(=193 / 418)$ \\
\hline $\begin{array}{l}\text { VFA: } m e n \geq 130 \text {; wom- } \\
\text { en } \geq 100\left(\mathrm{~cm}^{2}\right)\end{array}$ & $\begin{array}{c}37.8 \\
(=92 / 243)\end{array}$ & $\begin{array}{c}22.8 \\
(=40 / 174)\end{array}$ & $X^{2}(\mathrm{df} 1)=10.3$ & $<0.0001$ & $31.6(132 / 417$ \\
\hline \multicolumn{6}{|l|}{ 25(OH)D3 Status } \\
\hline Insufficiency (\%) & $\begin{array}{c}21.1 \\
(=52 / 246)\end{array}$ & $\begin{array}{c}31.0 \\
(=54 / 174)\end{array}$ & $X^{2}(\mathrm{df} 1)=5.3$ & 0.021 & $25.3(=106 / 420)$ \\
\hline Deficiency (\%) & $\begin{array}{c}35.5 \\
(=87 / 245)\end{array}$ & $\begin{array}{c}23.7 \\
(=41 / 173)\end{array}$ & $X^{2}(\mathrm{df} 1)=6.8$ & 0.009 & $30.6(=128 / 419)$ \\
\hline
\end{tabular}

As in Table 1, the prevalence of VFO was generally higher vary either in the age or TC levels. The prevalence of VFO and than obesity. Males had higher BMI, WC, VFA, SBP, and FPG levels VDD was higher in men, whereas the prevalence of obesity and than females. However, men were less obese and had lower vitamin D insufficiency was higher in women.

25(OH)D3 levels than females. Both sexes however did not

Table 2: Distribution of the study group by VFA quartiles in male subjects

\begin{tabular}{|c|c|c|c|c|c|}
\hline & \multicolumn{4}{|c|}{ Quartiles of VFA $\left(\mathrm{cm}^{2}\right)$} & \multirow[t]{2}{*}{ p-value } \\
\hline & $\begin{array}{c}\text { Q1 } \\
(<90.6)\end{array}$ & $\begin{array}{c}\text { Q2 (90.6- } \\
116.4)\end{array}$ & $\begin{array}{c}\text { Q3 (116.4- } \\
139.7)\end{array}$ & $\begin{array}{c}\text { Q4 } \\
(\geq 139.7)\end{array}$ & \\
\hline $\mathbf{n}$ & 59 & 70 & 60 & 57 & \\
\hline Age (y) (IQR) & $\begin{array}{l}41.4 \\
(10)\end{array}$ & $44.3(11)$ & $46.1(12)$ & $48.1(13)$ & 0.098 \\
\hline BMI $\left(\mathrm{kg} / \mathrm{m}^{2}\right)$ (IQR) & $25.5(4)$ & $28.8(5)$ & $30.2(4.8)$ & $\begin{array}{l}31.9 \\
(5.2)\end{array}$ & 0.034 \\
\hline WC (cm) (IQR) & $\begin{array}{l}86.6 \\
(5.2)\end{array}$ & $94.3(6.3)$ & $96.3(5.7)$ & $\begin{array}{l}103.4 \\
(7.1)\end{array}$ & 0.006 \\
\hline SBP (mmHg) (IQR) & $\begin{array}{c}119.9 \\
(11)\end{array}$ & $123.8(14)$ & $121.6(11)$ & $\begin{array}{c}124.9 \\
(13)\end{array}$ & 0.11 \\
\hline $\mathrm{TC}(\mathrm{mmol} / \mathrm{L})(\mathrm{IQR})$ & $\begin{array}{c}5.1 \\
(0.09)\end{array}$ & $6.0(1.0)$ & $6.3(1.2)$ & $6.6(1.3)$ & 0.007 \\
\hline FPG (mmol/L) (IQR) & $5.7(0.9)$ & $6.2(1.1)$ & $6.0(0.8)$ & $6.6(1.5)$ & 0.06 \\
\hline 25(OH)D3 ( $\mu \mathrm{g} / \mathrm{L})(\mathrm{IQR})$ & $\begin{array}{l}38.8 \\
(18)\end{array}$ & $31.4(15)$ & $28.8(16)$ & $23.2(14)$ & 0.005 \\
\hline
\end{tabular}




\section{Current Research in Diabetes \& Obesity Journal}

In Table 2, higher VFA quartiles encompassed higher men's BMI and WC indices. Men's TC observations also increased with VFA levels; while FPG did not. Age, SBP also did not significantly

Table 3a: Distribution of the study group by VFA quartiles in pre-menopausal women

\begin{tabular}{|c|c|c|c|c|c|}
\hline & \multicolumn{4}{|c|}{ Pre-Menopausal Quartiles of VFA $\left(\mathrm{cm}^{2}\right)$} & \multirow[b]{2}{*}{ p-Value } \\
\hline & $\begin{array}{c}\text { Q1 } \\
(<57.6) \\
\end{array}$ & $\begin{array}{c}\text { Q2 (57.6 - } \\
73.4)\end{array}$ & $\begin{array}{c}\text { Q3 (73.4 - } \\
90.2)\end{array}$ & $\begin{array}{c}Q 4 \\
(\geq 90.2)\end{array}$ & \\
\hline $\mathbf{n}$ & 28 & 36 & 32 & 29 & \\
\hline Age (y) (IQR) & $\begin{array}{l}32.3 \\
(6.5) \\
\end{array}$ & $35.2(8)$ & $37.1(7)$ & $39.2(6)$ & 0.06 \\
\hline BMI $\left(\mathrm{kg} / \mathrm{m}^{2}\right)(\mathrm{IQR})$ & $\begin{array}{l}22.9 \\
(1.8)\end{array}$ & $24.0(1.5)$ & $25.3(2)$ & $28.1(3)$ & 0.002 \\
\hline $\mathrm{WC}(\mathrm{cm})(\mathrm{IQR})$ & $\begin{array}{l}73.8 \\
(4.5) \\
\end{array}$ & $77.3(5)$ & $81.0(5.5)$ & $88.4(7)$ & 0.03 \\
\hline SBP (mmHg) (IQR) & $\begin{array}{c}100.7 \\
(11)\end{array}$ & $101.3(10)$ & $105.5(11)$ & $\begin{array}{c}109.8 \\
(13) \\
\end{array}$ & 0.02 \\
\hline $\mathrm{TC}(\mathrm{mmol} / \mathrm{L})(\mathrm{IQR})$ & $\begin{array}{c}4.5 \\
(0.7)\end{array}$ & $4.8(0.8)$ & $4.9(0,8)$ & $5.2(0.9)$ & 0.13 \\
\hline FPG (mmol/L) (IQR) & $\begin{array}{c}4.9 \\
(0.5) \\
\end{array}$ & $5.2(0.6)$ & $5.5(1.0)$ & $5.8(0.9)$ & 0.05 \\
\hline 25(OH)D3 ( $\mu \mathrm{g} / \mathrm{L})(\mathrm{IQR})$ & $\begin{array}{l}42.7 \\
(26)\end{array}$ & $41.2(25)$ & $36.8(21)$ & $\begin{array}{l}33.8 \\
(24)\end{array}$ & 0.003 \\
\hline
\end{tabular}

Table 3b: Distribution of the study group by VFA quartiles in post-menopausal women

\begin{tabular}{|c|c|c|c|c|c|}
\hline & \multicolumn{4}{|c|}{ Post-Menopausal Quartiles of VFA $\left(\mathrm{cm}^{2}\right)$} & \multirow[b]{2}{*}{ p-Value } \\
\hline & $\begin{array}{c}\text { Q1 } \\
(<77.5)\end{array}$ & $\begin{array}{c}\text { Q2 (77.5- } \\
99.1)\end{array}$ & $\begin{array}{c}\text { Q3 (99.1- } \\
125.2) \\
\end{array}$ & $\begin{array}{c}Q 4 \\
(125.2 \geq)\end{array}$ & \\
\hline $\mathbf{n}$ & 15 & 13 & 11 & 10 & \\
\hline Age (y) (IQR) & $57.68)$ & $58.7(6)$ & $58.2(5.5)$ & $58.9(4.8)$ & 0.34 \\
\hline BMI $\left(\mathrm{kg} / \mathrm{m}^{2}\right)(\mathrm{IQR})$ & $23.1(1.7)$ & $24.6(1.7)$ & $26.6(2.2)$ & $29.8(2.7)$ & 0.04 \\
\hline WC (cm) (IQR) & $78.6(4.5)$ & $82.5(2.3)$ & $87.3(4.5)$ & $96.6(6.4)$ & $<0.0001$ \\
\hline SBP (mmHg) (IQR) & $115.8(15)$ & $118.9(17)$ & $122.5(14)$ & $124.2(15)$ & 0.36 \\
\hline $\mathrm{TC}(\mathrm{mmol} / \mathrm{lL})(\mathrm{IQR})$ & $5.8(0.9)$ & $5.5(0.7)$ & $5.7(1.2)$ & $5.6(1.1)$ & 0.31 \\
\hline FPG (mmol/L) (IQR) & $5.4(1.3)$ & $5.8(1.1)$ & $6.1(1.5)$ & $5.8(0.9)$ & 0.43 \\
\hline $25(\mathrm{OH}) \mathrm{D} 3(\mu \mathrm{g} / \mathrm{L})(\mathrm{IQR})$ & $32.5(22.0)$ & $33.7(20.2)$ & $29.0(21.0)$ & $26(19.1)$ & 0.18 \\
\hline
\end{tabular}

As in Tables $3 a \& 3 b$, fatness covariates both in pre-menopausal women and post-menopausal peers were consistently associated with VFA quartiles; the higher VFA quartile the higher BMI and men, FPG levels did not associate VFA levels. Only pre-menstrual women had an inverse relationship between VFA and 25(OH) D3 levels, while post-menopausal peers did not.

WC. Age, SBP and TC did not vary between VFA quartiles. Unlike

Table 4: Vitamin D insufficiency (\%) status per VFA quartiles in the study group

\begin{tabular}{|c|c|c|c|c|c|}
\hline \multirow[t]{2}{*}{ 25(OH)D3 Insufficiency } & \multicolumn{4}{|c|}{ Men's VFA Quartiles $\left(\mathrm{cm}^{2}\right)$} & \multirow[t]{2}{*}{ p-Value } \\
\hline & $\begin{array}{c}\text { Q1 } \\
(<90.6)\end{array}$ & $\begin{array}{c}\text { Q2 (90.6- } \\
116.4)\end{array}$ & $\begin{array}{c}\text { Q3 (116.4- } \\
139.7)\end{array}$ & $\begin{array}{c}\text { Q4 } \\
(\geq 139.7)\end{array}$ & \\
\hline Prevalence (\%) & 10.1 & 13.3 & 37.7 & 39.8 & 0.002 \\
\hline \multicolumn{6}{|c|}{ Pre-Menopausal Women's VFA Quartiles $\left(\mathrm{cm}^{2}\right)$} \\
\hline & $\begin{array}{c}\text { Q1 } \\
(<57.6)\end{array}$ & $\begin{array}{c}\mathrm{Q} 2(57.6- \\
73.4)\end{array}$ & $\begin{array}{c}\text { Q3 (73.4 - } \\
90.2)\end{array}$ & $\begin{array}{c}\text { Q4 } \\
(\geq 90.2)\end{array}$ & \\
\hline Prevalence (\%) & 30.2 & 31 & 31.5 & 33.1 & 0.68 \\
\hline \multicolumn{6}{|c|}{ Post-Menopausal Women's VFA Quartiles $\left(\mathrm{cm}^{2}\right)$} \\
\hline & $\begin{array}{c}\text { Q1 } \\
(<77.5)\end{array}$ & $\begin{array}{c}\text { Q2 (77.5- } \\
99.1)\end{array}$ & $\begin{array}{c}\text { Q3 (99.1- } \\
125.2)\end{array}$ & $\begin{array}{c}\mathrm{Q} 4 \\
(125.2 \geq)\end{array}$ & \\
\hline Prevalence (\%) & 28.2 & 29.9 & 26.2 & 33.8 & 0.13 \\
\hline
\end{tabular}




\section{Current Research in Diabetes \& Obesity Journal}

Table 4 shows that men report an increasingly higher quartiles. However, such prevalence did not vary by preprevalence of 25(OH) D3 insufficiency across higher VFA menopausal-and post-menopausal women VFA.

Table 5: Vitamin D deficiency status per VFA quartiles of the study group

\begin{tabular}{|c|c|c|c|c|c|}
\hline \multirow[t]{2}{*}{ 25(OH)D3 Deficiency } & \multicolumn{4}{|c|}{ Men's VFA Quartiles $\left(\mathrm{cm}^{2}\right)$} & \multirow[t]{2}{*}{ p-Value } \\
\hline & $\mathrm{Q} 1(<90.6)$ & Q2 (90.6-116.4) & Q3 (116.4-139.7) & Q4 ( $\geq 139.7)$ & \\
\hline Prevalence (\%) & 20.1 & 39.6 & 45.2 & 55.3 & $<0,0001$ \\
\hline \multicolumn{6}{|c|}{ Pre-Menopausal Women's VFA Quartiles ( $\left.\mathrm{cm}^{2}\right)$} \\
\hline & $\mathrm{Q} 1(<57.6)$ & Q2 (57.6-73.4) & Q3 (73.4- 90.2) & Q4 ( $\geq 90.2)$ & \\
\hline Prevalence (\%) & 18.7 & 20.3 & 23.6 & 37.1 & 0.0003 \\
\hline \multicolumn{6}{|c|}{ Post-Menopausal Women's VFA Quartiles ( $\mathrm{cm}^{2}$ ) } \\
\hline & Q1 $(<77.5)$ & Q2 (77.5-99.1) & Q3 (99.1-125.2) & Q4 (125.2 $\geq)$ & \\
\hline Prevalence (\%) & 44.6 & 40.3 & 42.5 & 46.2 & 0.24 \\
\hline
\end{tabular}

The prevalence of VDD across VFA quartiles tended to values for men and pre-menopausal women were significantly, increase in men and only in pre-menopausal women (Table 5).

Table 6 shows the correlation between fatness indices and $25(\mathrm{OH})$ D3 level among the study groups. All reported 25(OH) D3

yet weakly correlated with corresponding BMI, WC and VFA levels. Post-menopausal women's 25(OH) D3; However, were not significantly correlated with all fatness indices.

Table 6: 25(OH) D3 level and fatness indices correlation: BMI, WC, VFA

\begin{tabular}{|c|c|c|c|}
\hline Group & Fatness Index & Rho & p-Value \\
\hline \multirow{3}{*}{ Men } & BMI $\left(\mathrm{kg} / \mathrm{m}^{2}\right)$ & -0.40 & 0.05 \\
\hline & $\mathrm{WC}(\mathrm{cm})$ & -0.36 & 0.05 \\
\hline & VFA $\left(\mathrm{cm}^{2}\right)$ & -0.38 & 0.05 \\
\hline \multirow{3}{*}{ Pre-menopausal women } & BMI $\left(\mathrm{kg} / \mathrm{m}^{2}\right)$ & -0.30 & $<0.05$ \\
\hline & $\mathrm{WC}(\mathrm{cm})$ & -0.90 & $<0.05$ \\
\hline & VFA $\left(\mathrm{cm}^{2}\right)$ & -0.20 & $<0.05$ \\
\hline \multirow{3}{*}{ Post-menopausal women } & BMI $\left(\mathrm{kg} / \mathrm{m}^{2}\right)$ & -0.05 & $>0.05$ \\
\hline & $\mathrm{WC}(\mathrm{cm})$ & -0.12 & $>0.05$ \\
\hline & VFA $\left(\mathrm{cm}^{2}\right)$ & -0.10 & $>0.05$ \\
\hline
\end{tabular}

Table 7: Fatness indices in vitamin-D insufficiency\& deficiency group combined by gender

\begin{tabular}{|c|c|c|c|c|c|c|}
\hline \multirow{2}{*}{ Gender } & \multirow{2}{*}{\multicolumn{2}{|c|}{ Fatness Index }} & \multirow{3}{*}{$\begin{array}{c}\begin{array}{c}\text { OR* } \\
\text { Lower }\end{array} \\
1\end{array}$} & \multicolumn{2}{|c|}{$95 \% \mathrm{CI}$} & \multirow{3}{*}{$\begin{array}{c}\text { p-value } * * * \\
----\end{array}$} \\
\hline & & & & Upper & & \\
\hline \multirow{7}{*}{ Men } & \multirow{2}{*}{ BMI } & $<30$ & & ---- & ---- & \\
\hline & & $\geq 30$ & 4.2 & 1.9 & 5.6 & 0.03 \\
\hline & \multirow{2}{*}{ WC } & $<102$ & 1 & $-\cdots--$ & ---- & ----- \\
\hline & & $\geq 102$ & 4.4 & 2.3 & 5.1 & 0.008 \\
\hline & \multirow{3}{*}{$\mathrm{VFA}^{* *}$} & Q2 (90.6-116.4) & 1.8 & 0.72 & 3.4 & 0.07 \\
\hline & & Q3 (116.4-139.7) & 4.1 & 2.3 & 5.9 & 0.01 \\
\hline & & Q4 ( $\geq 139.7)$ & 5.7 & 3.1 & 9.2 & 0.002 \\
\hline \multirow{7}{*}{ Pre-Menopausal Women } & \multirow{2}{*}{ BMI } & $<30$ & 1 & ---- & ----- & ----- \\
\hline & & $\geq 30$ & 4.2 & 2.2 & 7.2 & 0.003 \\
\hline & \multirow{2}{*}{ WC } & $<88$ & 1 & ---- & ---- & ---- \\
\hline & & $\geq 88$ & 3.6 & 2 & 4.7 & 0.02 \\
\hline & \multirow{3}{*}{$\mathrm{VFA}^{* *}$} & Q2 (57.6-73.4) & 1.5 & 0.61 & 2.5 & 0.45 \\
\hline & & Q3 (73.4-90.2) & 1.8 & 0.52 & 1.9 & 0.28 \\
\hline & & Q4 ( $\geq 90.2)$ & 3.4 & 1.2 & 4.5 & 0.009 \\
\hline
\end{tabular}




\section{Current Research in Diabetes \& Obesity Journal}

\begin{tabular}{|c|c|c|c|c|c|c|}
\hline \multirow{7}{*}{ Post-Menopausal Women } & \multirow{2}{*}{ BMI } & $<30$ & 1 & ----- & ----- & ----- \\
\hline & & $\geq 30$ & 2 & 0.95 & 3.6 & 0.06 \\
\hline & \multirow{2}{*}{ WC } & $<88$ & 1 & ----- & ----. & ---- \\
\hline & & $\geq 88$ & 1.4 & 0.78 & 2.1 & 0.37 \\
\hline & \multirow{3}{*}{$\mathrm{VFA}^{* *}$} & Q2 (77.5 - 99.1) & 1.1 & 0.26 & 1.9 & 0.65 \\
\hline & & Q3 (99.1-125.2) & 1.6 & 0.43 & 2.8 & 0.5 \\
\hline & & Q4 ( $\geq 125.2)$ & 1.5 & 0.73 & 2.3 & 0.25 \\
\hline
\end{tabular}

${ }^{*}$ OR for Q1 FVA levels for men and women categories = 1

${ }^{* *}$ OR $(95 \% \mathrm{Cl})$ VFA as one variable: Men: 2.3(1.4-3.2); Premenopausal: 1.7 (1.1-3.2), Postmenopausal: 1.4 (1.1-1.9).

${ }^{* * *}$-Value for trend: Men: <0.0001; Premenopausal: 0.009, Postmenopausal: 0.02

Table 7 exhibits the strength of association, measured by OR (95\% CI) between fatness indices and vitamin D inadequacy (insufficiency/deficiency) among the study gender groups. In men, all fatness indices significantly impacted 25(OH) D3 status. For instance, men with the highest VFA were at 5.7fold risk of 25(OH) D3 inadequacy compared with lowest VFA peers $(95 \%$ CI $3.1-9.2$; $\mathrm{p}=0.02)$. Likewise, the pre-menopausal women with highest VFA were 3.4-times prone to inadequate $25(\mathrm{OH})$ D3 concentrations than lowest VF peers $(95 \% \mathrm{CI}$ 2.2 - 4.5, p 0.009). Other fatness indices among these women were likewise significant correlates for inadequate vitamin-D levels. In post-menopausal women, all fatness indices did not significantly impact impaired vitamin-D status. Importantly, all study sex groups including post-menopausal women have shown a significant 25(OH) D3 insufficiency/deficiency trend vs. reported FVA levels.

\section{Discussion}

This work has been perfumed a midst an increasing concern of most healthcare systems and the research community about obesity [1-4], its precursors and nutritional and lifestyle correlates [7,9] and subsequent and health consequences $[5,6]$. The risks connected to obesity are countless, inflecting almost all health, metabolic, and nutritional aspects and body systems [19-30,37-40,58]. Especially the risk of deranged vitamin $\mathrm{D}$ concentration and metabolism in association with the risk of obesity is incriminated [12,14,23-30,34-39]. Whether there is a direct temporal relation between the two risks and that either risk can be cause to the other is still under thorough search [25,34,36-37]. A major determinant regulating vitamin D biophysiology involves exposure to UV light, where vitamin D3 (cholecalcifereol) is synthesized in the skin and then stored until needed [31]. While it would not be difficult to explain the probability of a high prevalence of vitamin $\mathrm{D}$ insufficiency/deficiency in cold climate zones with long winter and less sunrays [32], it would not be as easy to explain why VDD is likewise prevalent in zones with ample sunlight yearround [72-74]. In this study, we could confirm that VFO was significant risk impaired vitamin D level whether insufficiency and deficiency among the study population groups, namely men pre-menopausal women. Evidently, the greater VFO the greater would be the risk for vitamin D insufficiency or deficiency.

Vitamin D metabolism, including storage, distribution and action are now known to influence - and also be influenced by the individual's adiposity condition [14,23,30,34-39]. Particularly observational studies confirm the presence of such risk in people with central obesity $[11-14,36,75,76]$. Active 1,25(OH) D may influence the mobilization of FFAs from the adipose tissue [36]. Extensive research has shown that vitamin D2 supplementation in large doses may lead to increases in energy expenditure in adipose tissues [14-29,37-39,55,58]. Consistent with the this, our findings show that serum 25(OH) D3 level decreases in subjects with obesity and this decrease was closely correlated with fat distribution, particularly central obesity and VFO [11-14,36,75,76]. A large body of literature also concluded that 25(OH)D deficiency is a potential risk factor for obesity and the development of insulin resistance leading to type $2 \mathrm{DM}$ $[28,77,78]$.

Although the mechanism for the association between obesity and vitamin D insufficiency has not yet been explained, research strongly suggests that individuals with obesity are liable to vitamin D insufficiency/deficiency $[38,79,77,78]$, perhaps due to increased sequestration of the vitamin in the voluminous visceral adipose tissue in the obesity $[19,23,24,78]$. This may lead to less vitamin D released into the blood, and consequently these individuals may have lower serum $25(\mathrm{OH})$ D3 levels. These individuals may therefore need to increase their vitamin D intake to build up serum 25(OH) D3 levels comparable with individuals with normal BMI $[25,34,36]$. It has also been suggested that vitamin D insufficiency may stimulate lipogenesis as the result of increased calcium influx into the adipocytes mediated by increased synthesis of PTH. This further suggests that vitamin D insufficiency itself could cause obesity. Minimal outdoor activity and maximum skin covering by clothing among obese persons also limits photochemical subcutaneous synthesis of vitamin D [31,32]. Studies indicate that higher BMI has been associated with lowered vitamin D status [37], providing evidence for the role of obesity as a causal risk factor for the development of VDD on genetic basis [7,8], particularly based on bi-directional genetic approach [37]. 


\section{Current Research in Diabetes \& Obesity Journal}

Astrong association between VFA and vitamin D insufficiency/ VDD has been found in this study; however its temporal nature could not be ascertained in presence of a cross-sectional design. Further, this study provides evidence for an expectedly inverse association between VFA and serum 25(OH) D3 among the study's sex groups, namely men and pre-menopausal women. Similar finding were also recorded in equivalent European [79] and southeast Asian studies [80]. Moreover, our study was able to incorporate both men and women and further adjust for the effect of menopause upon women's vitamin D status. Particularly male subjects have been susceptible to vitamin D insufficiency/deficiency on top of increased VFO standard and other elevated fatness indices levels. Likewise, the prevalence of both obesity and VFO in men was higher than that in women, the mechanism of which may well be explained by the sequestration and dilution effect of the adipose tissue upon vitamin D content [78]. There was likewise a significant difference in VDD in association with VFA quartiles among pre-menopausal but not among post-menopausal peers. However, an overall significant 25(OH) D3 insufficiency/deficiency trend has been found in postmenopausal women when FVA was handled as an overall VFA but not VFA quartiles. Other studies addressed an impaired vitamin D status in post-menopausal-age women [39].

The relatively small number of post-menopausal women in our study (49 subjects), may have been the reason why the analysis could not reveal a significant relationship. In the longitudinal study by Leblanc et al. [39] more than 9000 women were recruited to determine the relation between $25(\mathrm{OH}) \mathrm{D}$ and weight gain. While our study targeted men and women of all adult age range, Leblanc and collaborates were only concerned with old-age candidates. Studies endorse the close link between impaired 25(OH) D3 concentration and both obesity and linked chronic and metabolic diseases, e.g., hyperlipidemia, HTN, and T2DM; $[21-30,38,40]$ and the subsequent increased likelihood of developing CVD $[25,81,82]$. Likewise, researches on the vitamin D-metabolic syndrome complex are being performed largely. For instance, serum vitamin D3 levels were significantly lower in a patient group with a metabolic syndrome complex compared with the non-metabolic syndrome counterpart [83].

Lower vitamin D3 levels were likewise associated with metabolic syndrome components, such as obesity, HTN, IGT, as well as an increase in homeostasis model assessment of insulin resistance (HOMA-IR), and especially obesity was highly associated with such insulin resistance and low vitamin D3 levels in comparison with normal weight subjects $[21,23,25,27,38]$. Actually, active release of FFAs from adipose tissue can induce insulin resistance, whereas $1,25(\mathrm{OH}) \mathrm{D}$ has been shown to counteract the FFA-induced insulin resistance $[36,42,50,57]$. Further, larger VFA levels and VFO have been related to a higher prevalence of metabolic risk factors including IGT [83], DM, insulin resistance $[19,22,28,29,38]$ and dyslipidemia $[20,27,30,40]$.
Now that vitamin D has been strongly and consistently associated with insulin resistance in VFO patients, an adequately maintained vitamin D status may well be an effective measure for preventing the group of metabolic consequences congruent with insulin resistance encountered by those patients. In our study, too, a tendency for an increasingly high FPG with increasing VFA quartiles has been reported in both genders. Further, high VFA scores were associated with the selected metabolic disorders parameters. The positive dose-response found between impaired FPG and VFA in our study is consistent with that found in literature. For instance, it has been reported that VFA was a major determinant of metabolic syndrome in premenopausal Korean women [83], whereas WC and VFA were both similarly useful in identifying metabolic syndrome in elderly women. Our findings with this regard may well be considered, e.g., planning for a screening program for an early detection of VDD and related health problems, using VFA as a simple meanwhile costeffective tool.

In this work, using sophisticated body-components assessment measures, such as DEXA or CT to measure VFO was not resorted, opting to avoid radiation exposure when safer measures such as BIA if used provide a reasonably equivalent alternative to achieve study aim. Providing further data about the temporal pattern of the relationship between vitamin $\mathrm{D}$ concentrations and VFA may have been limited by the inability to follow up the participants' nutritional status over time. From the biochemical standpoint, there was a principal focus on 25(OH) D3 per se disregarding the detailed interaction between vitamin D and the subjects' iPTH. That is why we opted to not adjust for iPTH in analyzing the relationship between central obesity and 25(OH) D3. Some of the study's data, particularly the menopausal inquiry, were based on self-reporting, in which case recall bias could be a concern.

Part of the current obesity-vitamin D project plan, a prospective research is contemplated to further analyze the relations between VFA and impaired vitamin D levels. A cohort of individuals followed up for a sufficient time interval; their baseline vitamin $\mathrm{D}$ and weight taken and analyzed would help provide strong evidence about the relationship and direction of causality between obesity and VDD in risk population groups. Overall, a significant association between increased VFA and the risk of impaired vitamin among Upper Egypt's male adult population and females peers younger than menopause has been revealed on scientific anthropometric and biochemical analyses basis. This study supports the notion that VFA assessed by BIA could be a reliable index for measuring visceral adiposity, a process which could be incorporated routine medical checkup in order to detect the risk of impaired vitamin D levels among the Egyptian populations.

\section{References}

1. (2011) Noncommunicable Diseases Country Profiles. World Health Organisation, Geneva, Switzerland, p. 209. 


\section{Current Research in Diabetes \& Obesity Journal}

2. (2016) Obesity and overweight. Fact sheet, World Health organization (WHO).

3. James P (2003) International Obesity Task Force, Monte Carlo.

4. James WPT, Chunming C, Inoue S (2002) Appropriate Asian body mass indices? Obes Rev 3(3): 139.

5. Sanada H, Yokokawa H, Yoneda M, Yatabe J, Sasaki Yatabe M, et al. (2012) High body mass index is an important risk factor for the development of type 2 diabetes. Intern Med 51(14): 1821-1826.

6. Kuhlmann HW, Falconi RA, Wolf AM (2000) Cost-effective bariatric surgery in Germany today. Obes Surg 10(6): 549-552.

7. Phan-Hug F, Beckmann JS, Jacquemont S (2012) Genetic testing in patients with obesity. Best Pract Res Clin Endocrinol Metab 26(2): 133-143.

8. Qin X, Zhang Y, Cai Y, He M, Sun L, et al. (2012) Prevalence of obesity, abdominal obesity and associated factors in hypertensive adults aged 45-75 years. Clin Nutr 32(3): 361-372.

9. Parikh SJ, Edelman M, Uwaifo GI, Freedman RJ, Semega-Janneh M, et al. (2004) The relationship between obesity and serum 1,25-dihydroxy vitamin D concentrations in healthy adults. J Clin Endocrinol Metab 89(3): 1196-1199.

10. Ailshire JA, House JS (2011) The Unequal Burden of Weight Gain: An Intersectional Approach to Understanding Social Disparities in BMI Trajectories from 1986 to 2001/2002. Social Forces 90(2): 397-423.

11. Akpinar E, Bashan I, Bozdemir N, Saatci E (2007) Which is the best anthropometric technique to identify obesity: body mass index, waist circumference or waist-hip ratio? Coll Anthropol 31(2): 387-393.

12. Zhang M, Li P, Zhu Y, Chang H, Wang X, et al. (2015) Higher visceral fat area increases the risk of vitamin $D$ insufficiency and deficiency in Chinese adults. Nutr Metab (Lond) 12: 50.

13. Vazquez G, Duval S, Jacobs DR, Silventoinen K (2007) Comparison of body mass index, waist circumference, and waist/Hip ratio in predicting incident diabetes. Meta-Analysis Epidemiol Rev 29: 115 128

14. (2014) Obesity: identification, assessment and management. Clinical guideline. National Institute for Health and Care Excellence (NICE).

15. Siri WE (1961) Body composition from fluid space and density. In: J Brozek \& A Hanschel (Eds.), Techniques for measuring body composition. DC: National Academy of Science, Washington, USA, pp 223-244.

16. Arunabh S, Pollack S, Yeh J, Aloia JF (2003) Body fat content and 25-OHD levels in healthy women. J Clin Endocrinol Metab 88(1): 157-161.

17. Kiebzak GM, Leamy LJ, Pierson LM, Nord RH, Zhang ZY (2000) Measurement precision of body composition variables using the lunar DPX-L densitometer. J Clin Densitom 3(1): 35-41.

18. Iwaoka H, Yokoyama T, Nakayama T, Matsumura Y, Yoshitake Y, et al. (1998) Determination of percent BF by the newly developed sulfur hexafluoride dilution method and air displacement plethysmography. J Nutr Sci Vitaminol (Tokyo) 44(4): 561-568.

19. Adams JS, Hewison M (2010) Update in vitamin D. J Clin Endocrinol Metab 95(2): 471-478.

20. Holick MF (2006) High prevalence of vitamin D inadequacy and implications for health. Mayo Clin Pro 81(3): 353-373.

21. Heaney RP (2008) Vitamin D in health and disease. Clin J Am Soc Nephrol 3(5): 1535-1541.

22. Pittas AG, Lau J, Hu FB, Dawson-Hughes B (2007) The Role of Vitamin D and Calcium in Type 2 Diabetes. A Systematic Review and MetaAnalysis. J Clin Endocrinol \& Metab 92(6): 2017-2029.
23. Bikle D (2008) Nonclassic Actions of Vitamin D. J Clin Endocrinol \& Metab 94(1): 26-34.

24. Holick MF (2007) Vitamin D Deficiency. New Engl J Med 357(3): 266281.

25. McGill AT, Stewart JM, Lithander FE, Strik CM, Poppitt SD (2008) Relationships of low serum vitamin D3 with anthropometry and markers of the metabolic syndrome and diabetes in overweight and obesity. Nutrition Journal 7: 1-5.

26. (2001) Executive Summary of the Third Report of the National Cholesterol Education Program (NCEP) Expert Panel on Detection, Evaluation, and Treatment of High Blood Cholesterol in Adults (Adult Treatment Panel III). J Am Med Ass 285(19): 2486-2497.

27. Forman JP, Curhan GC, Taylor EN (2008) Plasma 25-hydroxyvitamin D levels and risk of incident hypertension among young women. Hypertension 52(5): 828-832.

28. Chiu KC, Chu A, Go VLW, Saad M (2004) Hypovitaminosis D is associated with insulin resistance and $\beta$ cell dysfunction. Am J Clin Nutr 79(5): 820-825.

29.Sun X, Zemel MB (2008) 1Alpha,25-dihydroxyvitamin D and corticosteroid regulate adipocyte nuclear vitamin D receptor. Int J Obes 32(8): 1305-1311.

30. De Paula FJA, Rosen CJ (2011) Vitamin D and fat. In Vitamin D. In: Feldman D, Pike JW, Adams JS (Eds.), Academic Press, pp. 769-776.

31. Denio A (2017) Vitamin D Deficiency: The Silent Epidemic of the Elderly. The International Society for Clinical Densitometry.

32. Thomas MK, Lloyd-Jones DM, Thadhani RI, Shaw AC, Deraska DJ, et al. (1998) Hypovitaminosis D in medical inpatients. N Eng J Med 338(12): 777-783.

33. Tangpricha V, Pearce EN, Chen TC, Holick MF (2002) Vitamin D Insufficiency among Free-Living Healthy Young Adults. Am J Med 112(8): 659-662

34. Liel Y, Ulmer E, Shary J, Hollis B, Bell N (1988) Low circulating vitamin D in obesity. Calcif Tissue Int 43(4): 199-201.

35. Lagunova Z, Porojnicu A, Lindberg F, Hexeberg S, Moan J (2009) The dependency of vitamin D status on body mass index, gender, age and season. Anticancer Res 29(9): 3713-3720.

36. Vimeswaran K, Berry D, Lu C, Pilz S, Hiraki L, et al. (2013) Causal relationship between obesity and vitamin $\mathrm{D}$ status: Bi-directional mendelian randomization analysis of multiple cohorts. PLoS Med 10: 1549-1676.

37. Vanlint S (2013) Vitamin D and Obesity. Nutrients 5(3): 949-956.

38. Pinelli N, Jaber L, Brown M, Herman W (2010) Serum 25-hydroxy vitamin $\mathrm{D}$ and insulin resistance, metabolic syndrome, and glucose intolerance among Arab Americans. Diabetes Care 33(6): 1371-1375.

39. Leblanc ES, Rizzo JH, Pedula KL, Ensrud KE, Cauley J, et al. (2012) Associations between 25-hydroxyvitamin D and weight gain in elderly women. J Women Health 21(10): 1066-1073.

40. Mai XM, Chen Y, Camargo CA Jr, Langhammer A (2012) Cross-sectional and prospective cohort study of serum 25-hydroxyvitamin D level and obesity in adults: the HUNT study. Am J Epidemiol 175(10): 10291036.

41. Takahashi N, Udagawa N, Suda T (2014) Vitamin D endocrine system and osteoclasts. BoneKEy Reports 3: 495.

42. Holick MF (1999) Vitamin D: Photobiology, Metabolism, Mechanism of Action, and Clinical Applications. In: Murray Favus, (Edt.), Primer on the Metabolic Bone Diseases and Disorders of Mineral Metabolism. (edn 4), Lippincott Williams \& Wilkens. Philadelphia, USA, p. 92-98. 


\section{Current Research in Diabetes \& Obesity Journal}

43. Heany RP (2003) Calcium Absorption Varies within the Reference Range for Serum 25-Hydroxyvitamin D. J Am Coll Nutr 22(12): 142-146.

44. Mithal A, Wahl DA, Bonjour JP, Burckhardt P, Dawson-Hughes B, et al. (2009) Global vitamin D status and determinants of hypovitaminosis D. Osteoporos Int 20(11): 1807-1820.

45. Wahl DA, Cooper C, Ebeling PR, Eggersdorfer M, Hilger J, et al. (2012) A global representation of vitamin D status in healthy populations. Arch Osteoporos 7(1-2): 155-172.

46. Al-Turki HA, Sadat-Ali M, Al-Elq AH, Al-Mulhim FA, Al-Ali AK (2008) 25-Hydoxyvitamin D levels among healthy Saudi Arabian women. Saudi Med J 29(12): 1765-1768.

47. Wilkins CH, Sheline YI, Roe CM, Birge SJ, Morris JC (2006) Vitamin D Deficiency is Associated with Low Mood and Worse Cognitive Performance in Older Adults. Am J Geriatr Psychiatry 14(12): 1032 1040.

48. Anglin RE, Samaan Z, Walter SD, McDonald SD (2013) Vitamin D deficiency and depression in adults: systematic review and metaanalysis. Br J Psychiatry 202: 100-107.

49. Hawkins EB, Ehrlich S (2007) Possible Interactions with: Vitamin D.

50. Malloy P, Feldman D (2010) Genetic Disorders and Defects in Vitamin D Action. Endocrinol Metab Clin North Am 39(2): 333-346.

51. (2013) National Institute for Health and Care Excellence. BMI: preventing ill health and premature death in black, Asian and other minority ethnic groups. Public health guideline [PH46].

52. Lips P, Chapuy MC, Dawson-Hughes B, Pols HA, Holick MF (1999) An international comparison of serum 25-hydroxyvitamin D measurements. Osteoporos Int 9(5): 394-397.

53. Trivedi DP, Doll R, Khaw KT (2003) Effect of four monthly oral vitamin D3 (cholecalciferol) supplementation on fractures and mortality in men and women living in the community: randomised double blind controlled trial. BMJ 326(7307): 469

54. Jeffery RW, French SA (1999) Preventing weight gain in adults: the pound of prevention study. AJ PH 89: 747-751.

55. Ding C, Gao D, Wilding J, Trayhurn P, Bing C (2012) Vitamin D signalling in adipose tissue. Br J Nutr 108(11): 1915-1923.

56. Wamberg L, Cullberg KB, Rejnmark L, Richelsen B, Pedersen SB (2013) Investigations of the anti-inflammatory effects of vitamin $\mathrm{D}$ in adipose tissue: results from an in vitro study and a randomized controlled trial Horm Metab Res 45(6): 456-462.

57. Abdelkarem HM, El-Sherif MA, Gomaa SB (2016) Vitamin D status and insulin resistance among young obese Saudi females. Saudi Med J 37(5): 561-566.

58. American Society for Metabolic and Bariatric Surgery. Who is a Candidate for Bariatric Surgery.

59. Sasse KC, Ganser J, Kozar M, Watson RW, McGinley L, et al. (2008) Seven cases of gastric perforation in Roux-en-Y gastric bypass patients: what lessons can we learn? Obes Surg 18(5): 530-534.

60. Ellsmere JC, Jones D, Chen W (2017) Late complications of bariatric surgical operations.

61. Bloomberg RD, Fleishman A, Nalle JE, Herron DM, Kini S (2005) Nutritional deficiencies following bariatric surgery: what have we learned. Obes Surg 15(2): 145-154.

62. Malabanan M, Veronikis IE, Holick MF (1998) Redefining vitamin D insufficiency. Lancet 351(9105): 805-806.

63. (2006) Behavioral Risk Factor Survey Module: Definitions of Survey Measures. Wisconsin Behavioral Risk Factors Survey.
64. World Health Organization. WHO STEP wise approach to chronic disease risk factor surveillance- Instrument v2.0. Department of Chronic Diseases and Health Promotion. WHO.

65. (2002) National Cholesterol Education Program. Third Report of the Expert Panel on Detection, Evaluation, and Treatment of High Blood Cholesterol in Adults (ATP III Final Report). National Institutes of Health. p. 11-27.

66. Kang SH, Cho KH, Park JW, Yoon KW, Do JY (2015) Association of visceral fat area with chronic kidney disease and metabolic syndrome risk in the general population: analysis using multi-frequency bioimpedance. Kidney Blood Press Res 40(3): 223-230.

67. Shoji K, Maeda K, Nakamura T, Funahashi T, Matsuzawa Y, et al. (2008) Measurement of visceral fat by abdominal bioelectrical impedance analysis is beneficial in medical checkup. Obes Res Clin Pract 2(4): 1-2

68. Kim TN, Park MS, Kim YJ, Lee EJ, Kim MK, et al. (2014) Association of low muscle mass and combined low muscle mass and visceral obesity with low cardiorespiratory fitness. PLoS One 9(6): e100118.

69. Gallagher JC, Sai AJ (2010) Vitamin D insufficiency, deficiency, and bone health. J Clini Endocrinol Metab 95(6): 2630-2633.

70. Shils ME, Shike M (2006) Modern Nutrition in Health and Disease. (Edn 1), Lippincott Williams \& Wilkins: Philadelphia, USA.

71. Muhairi SJ, Mehairi AE, Khouri AA, Naqbi MM, Maskari FA, et al. (2013) Vitamin D deficiency among healthy adolescents in Al Ain, United Arab Emirates. BMC Public Health 13: 33.

72. Hwalla N, Al Dhaheri AS, Radwan H, Alfawaz HA, Fouda MA, et al. (2017) The Prevalence of Micronutrient Deficiencies and Inadequacies in the Middle East and Approaches to Interventions. Nutrients 9(3): 229.

73. Al-Jurayyan NA, Elidrissy E, Sandokji AM, Al-Magamsi MSA, AlHawsawi ZM (2002) Nutritional rickets and osteomalacia in school children and adolescents. Saudi Med J 23(2): 182-185

74. Earthman CP, Beckman LM, Masodkar K, Sibley SD (2012) The link between obesity and low circulating 25-hydroxyvitamin D concentrations: considerations and implications. Int J Obes (Lond) 36(3): 387-396

75. Fredriks AM, van Buuren S, Fekkes M, Verloove-Vanhorick P, Wit JM (2005) Are age references for waist circumference, hip circumference and waist-hip ratio in Dutch children useful in clinical practice? Eur J Pediatr 164(4): 216-222.

76. Pittas AG, Lau J, Hu FB, Dawson-Hughes B (2007) The Role of Vitamin $\mathrm{D}$ and Calcium in Type 2 Diabetes. A Systematic Review and MetaAnalysis. J Clin Endocrinol \& Metab 92(6): 2017-2029.

77. Wortsman J, Matsuoka LY, Chen TC, Lu Z, Holick MF (2000) Decreased bioavailability of vitamin D in obesity. Am J Clin Nutr 72(3): 690-693.

78. Hannemann A, Thuesen BH, Friedrich N, Völzke H, Steveling A, et al. (2015) Adiposity measures and vitamin D concentrations in Northeast Germany and Denmark. Nutr Metab (Lond) 12: 24.

79. Hao Y, Ma X, Shen Y, Ni J, Luo Y, et al. (2014) Associations of serum 25-hydroxyvitamin D3 levels with visceral adipose tissue in Chinese men with normal glucose tolerance. PLoS One 9(1): e86773.

80. Yin X, Sun Q, Zhang X, Lu Y, Sun C, et al. (2012) Serum 25(OH) D is inversely associated with metabolic syndrome risk profile among urban middle-aged Chinese population. Nutr J 11: 68.

81. Baker JF, Mehta NN, Baker DG, Toedter G, Shults J, et al. (2012) Vitamin $\mathrm{D}$, metabolic dyslipidemia, and metabolic syndrome in rheumatoid arthritis. Am J Med 125(10): 1036.e9-1036.e15.

82. Forouhi NG, Luan J, Cooper A, Boucher BJ, Wareham NJ (2008) Baseline serum 25-hydroxy vitamin d is predictive of future glycemic status and 


\section{Current Research in Diabetes \& Obesity Journal}

insulin resistance: the Medical Research Council Ely Prospective Study 1990-2000. Diabetes 57(10): 2619-2625.
83. Hyun YJ, Kim OY, Jang Y, Ha JW, Chae JS, et al. (2008) Evaluation of metabolic syndrome risk in Korean premenopausal women: not waist circumference but visceral fat. Circ J 72(8): 1308-1315.

\section{Your next submission with Juniper Publishers} will reach you the below assets

- Quality Editorial service

- Swift Peer Review

- Reprints availability

- E-prints Service

- Manuscript Podcast for convenient understanding

- Global attainment for your research

- Manuscript accessibility in different formats

( Pdf, E-pub, Full Text, Audio)

- Unceasing customer service

Track the below URL for one-step submission https://juniperpublishers.com/online-submission.php 